\title{
PREVALENCE OF GEOHELMINTHES IN SCHOOL CHILDREN IN SOME PARTS OF LOKOJA, KOGI STATE, NORTH-CENTRAL NIGERIA
}

\author{
*Shitta, K.B., Audu, H.O. and Usman, A.Y. \\ ${ }^{1}$ Department of Biological Sciences, Federal University Lokoja, \\ P.M.B. 1154, Lokoja, Kogi State, Nigeria. \\ *Corresponding author: kefasshitta@yahoo.com; kefas.shitta@fulokoja.edu.ng 甶: 08034391987;
} 08026365158

\begin{abstract}
Geohelminthes are soil transmitted parasites and a major public health challenge in children, particularly in the tropical and sub-tropical regions of the world where sanitary conditions are poor. A study to determine the prevalence of geohelminthes infections among school children in parts of Lokoja Local Government Area of Kogi State was carried out. Stool specimens were collected from 254 school children in two primary schools and examined using standard concentration method. School children were randomly selected for the study. The overall prevalence of geohelminthes recorded was $58.30 \%$. Five Geohelminthes were observed in order of prevalence; Fasciola spp (33.10\%), Trichiuris trichiura (24.30\%), Ascaris lumbricoides (21.60\%), Hookworm (18.20\%) and Enterobius vermicularis (2.70\%). The prevalence rate in males was higher $(37.80 \%)$ than that of the females $(20.50 \%)$ and statistics significantly different $\left(x^{2}=3.841, p<0.05\right)$. The public school showed the highest infection rate $(73.60 \%)$, while the private school assumed the least prevalence of (42.40\%). Chi-square analysis showed a significant difference in the infection among the schools $\left(x^{2}=3.841\right.$, $p<0.05)$. Based on these findings, mass treatment of school children, health education campaign, improved sanitary condition, provision of toilet facilities and personal hygiene were recommended as control and prevention measures.
\end{abstract}

Keywords: Prevalence, Geohelminthes infection, Lokoja, Kogi State.

\section{INTRODUCTION}

Geohelminthes are soil transmitted parasites where immature or underdeveloped stages (eggs) require a minimum period of development or incubation in the soil before they become infective. The commonest and well known of such parasites are Ascaris lumbricoides, Trichuris trichiura, Hookworm, Fasciola spp and Enterobius vermicularis (Eke etal., 2015). Geohelminth infection is a major public health challenge in children, particularly in the tropical and sub-tropical regions of the world where sanitary conditions are poor (Obiukwu, et al., 2008; Shitta et al., 2017). Soil-transmitted parasites infection is approximately one billion people world-wide with school children being the most infected group. It is estimated that over one billion people are affected with Ascaris lumbricoides, 800 million people with Hook worm, and 770 million people with Trichuris trichiura (WHO 1998; Ogbeetal., 2002).

Varying prevalences had been recorded by reports in different parts of Africa for geohelminths (Glickman, etal., 1999; Dada-
Adegbola, et al., 2005; Ndamukong, et al., 2000 and Ndenecho, et al., 2002). In some parts of Nigeria reports by Anumba, et al., 2016, Eke, etal., 2015, Shitta, et al., 2017 and Badaki, et al., 2005 all showed a high prevalence rate of $63.16 \%, 67.08 \%, 74.20 \%$ and $94.70 \%$ respectively for intestinal helminths. Infections with intestinal helminths has been associated with stunting of linear growth, weakness and cognitive impairment in school children (Stephenson, 1994 and Merid-Hegasy, et al., 2001) education in host resistance to other disease causing agents (Feachem, et al., 1991), anaemia, intestinal obstruction, malnutrition, Trichuris dysentery syndrome (TDS), fever. Geohelminth is the second leading cause of death among children $<6$ years of age in Africa (Eke, etal., 2015).

The infection is promoted by poor sanitary habits such as indiscriminate dumping or disposal of human and animal faeces. This habit permits contact of faeces and its accompanying and microbial load together with geohelminth eggs with soil. Other risk factors include lack of safe water source, over-crowding, poverty, 
geophagia, failure to wear shoe, having pools of water and sewage around houses (Phiri, etal., 2002).

In Nigeria, a considerable amount of human and animal waste is discharged daily into the soil leading to the seeding of the soil with pathogenic organisms including geohelminth eggs and larvae. Infection may be direct or indirect through secondary sources as food, water, vegetables and fruits since most geohelminth infections are acquired through the faeca-oral route (Eke, etal., 2015).

The distribution and prevalence of various species of intestinal helminths differ from region to region. Although several studies have been conducted on the distribution and prevalence of intestinal helminth parasites in Nigeria; there are still many localities for which epidemiological information is not available. This study was therefore, carried out in order to enrich baseline data on the occurrence and magnitude of geohelminths infections among primary school children in the study-area, and to highlight the need for proper waste disposal facilities with a view towards maintaining a high standard of personal and environmental hygiene.

\section{MATERIALS AND METHODS Study area}

This study was conducted in two (2) primary schools one public and one private within Lokoja metropolis. Lokoja the capital city of Kogi State lies between longitude $7^{0} 49$ North and latitude $6^{\circ} 44$ East of the equator. Lokoja has a total land area of about 29,833 sq. $\mathrm{km}$. Lokoja originally called the confluence town, existed as a farming settlement prior to the colonial administration period in 1800. (Kogi State Diary, 2015). The inhabitants generally are civil servant, mainly fishermen and peasant farmers. The community is close to a river source, which is the main source of water supply where both adult and children carry out their domestic and recreational activities (washing, bathing and swimming).

It is an area with moderate amount of rainfallof about $1270 \mathrm{~mm} /$ annual which last for seven months and also a dry season which exceeds the rainy season, with an average temperature of $34^{\circ} \mathrm{C}$ annually (Federal University Lokoja Meteorological Centre, 2015).

\section{Ethical clearance for the study}

Ethical clearance was obtained from the Kogi State Ministry of Health and the Head Masters of the primary schools in the study area gave approval for this study.

\section{Collection of stool sample}

Plastic bottles (wide-mouth) were given to 254primary school pupils selected randomly. The pupils were allowed to take the bottles home and return same the next day (in the morning) to school with freshly passed stool samples. The name, age, and sex of each pupil were noted after the sample has been collected and labelled.The stool samples were preserved with $10 \%$ formalin and transferred to the Biologylaboratory of the Federal University Lokoja, for analysis.

\section{Examination of stool sample Concentration method or technique}

The concentration method was used to concentrate helminths eggs in $1 \mathrm{~g}$ of the faeces. $1 \mathrm{~g}$ of stool sample was mixed with $10 \mathrm{ml}$ of normal saline using an applicator stick to form a suspension. The suspension was filtered into a test-tube and centrifuged at 1,000 revolutions per minute for 1 minute $(1,000 \mathrm{rpm})$. The supernatant was discarded. About $3-4 \mathrm{ml}$ of $10 \%$ formol solution was added to the deposit to form a homogenous suspension and the mixture was allowed to stand for 5minutes on the length. A $3-4 \mathrm{ml}$ of diethyl ether was added and shaken vigorously and allowed to stand for 2 minutes, it was then centrifuged at 1,000 revolutions per minute for 1 minute. The faecal debris from the slide of the tube was detached with the aid of a glass rod (spatula) and the supernatant discarded leaving the deposit at the bottom of the centrifuge tube. The deposit was tapped with finger to mix and using a Pasteur pipette, a drop of the deposit was applied on a microscope slide mixed with lugol's iodine, covered with a cover slip and examined using $\times 10$ objective lens while the x40 objective lens was used for identification of eggs (WHO 1991; Cheesbrough, 1992 and Oyerinde, 1999).

\section{Statistical analysis}

The data in this study were processed using Statistical Package for Social Sciences (SPSS 20). Associations between demographic attributes and parasite type were tested. The proportions obtained in the study were compared using chi-square test. The confidence level for the analysis was set at $95 \%$, and level of significant difference at $p<0.05$. 


\section{RESULTS AND DISCUSSION}

Two hundred and fifty four (254) pupils were examined for geohelminths, 148(58.30\%) were found to be positive for eggs/larvae of geohelminthes. The helminthes encountered in order of prevalence include; Fasciolopsis spp with highest prevalence of $49(33.10 \%)$, followed by $T$. trichiura 36(24.30\%), A. lumbricoides had a prevalence of $32(21.60 \%)$, Hookworm $27(18.2 \%)$ and $E$. vermicularis had the lowest prevalence of $4(2.70 \%)$ (Table 1$)$ which is in agreement with the findings of Anumba et al., 2016 and Shitta, et al., 2017.

On the contrary, the prevalence in this study was lower compared to the findings of Badaki, et al., 2005, who recorded a prevalence of $94.70 \%$ among primary school children in Zing and Yorro towns, Taraba State Nigeria, this was because of the level of awareness and few toilet facilities provided by the schools visited. The result of this study also agrees with the prevalence recorded by Eke, etal., 2015 who reported a prevalence of $67.08 \%$. This observation is expected because of the differences in sampling methods, environmental conditions, and the degree of dispersion of eggs. The average level of sanitation in the study area is commendable but can be improved upon. Generally, this prevalence has been attributed by several authors to improper hygiene, poverty, poor sanitary conditions and agricultural habits, physical and chemical composition of the soil and degree of human exposure (Erko, and Medhin, 2003 and Ugbomoiko, et al., 2006).

Table 1 further revealed a higher helminths infection in the public school 95(73.60\%) when compared to their private school counterpart with about 53(42.40\%). There was a statistic significant difference in the infection prevalence between the public and private schools $(p<0.05)$. An industrial action often embarked upon in public schools within the state may have exposed the pupils to geohelminths infection, since the play a lot during the strike action before returning to school when actions are suspended.

Table 1.prevalence of geohelminthes parasite in public and private school

\begin{tabular}{|c|c|c|c|c|c|c|c|}
\hline School & $\begin{array}{l}\text { No. of } \\
\text { Sample } \\
\text { examine } \\
\text { d }\end{array}$ & $\begin{array}{l}\text { No. of } \\
\text { sample } \\
\text { Positive } \\
\text { (\%) }\end{array}$ & $\begin{array}{l}\text { Fasciola } \\
\text { sp } \\
\\
\quad(\%)\end{array}$ & $\begin{array}{l}\text { Trichuristri } \\
\text { chiura } \\
\text { (\%) }\end{array}$ & $\begin{array}{l}\text { Parasite } \\
\text { Enterobius } \\
\text { vermicularis } \\
\qquad(\%)\end{array}$ & $\begin{array}{l}\text { types } \\
\text { Hook } \\
\text { worm (\%) }\end{array}$ & Asl (\%) \\
\hline Public & 129 & $\begin{array}{c}95 \\
(73.6)\end{array}$ & $26(27.4)$ & $21(22.1)$ & - & $16(16.8)$ & $32(33.7)$ \\
\hline Private & 125 & $\begin{array}{c}53 \\
(42.4)\end{array}$ & $23(43.4)$ & $15(28.3)$ & $4(7.5)$ & $11(20.8)$ & - \\
\hline Total & 254 & $\begin{array}{c}148 \\
(58.3) \\
\end{array}$ & $49(33.1)$ & $36(24.3)$ & $4(2.7)$ & $27(18.2)$ & $32(21.6)$ \\
\hline
\end{tabular}

Of 254 stool samples analysed, one hundred and forty six $146(57.48 \%)$ were obtained from males and $108(42.52 \%)$ from females. Out of a total 254 stools collected and analysed, one hundred and forty eight (148) were positive for one or more helminthes infections. The overall prevalence of infection was $58.30 \%$.

In this study, male had the highest prevalence of $96(37.80 \%)$ compared to their female counterpart with about 52(20.05\%). There was a significant difference observed in infection among the gender group ( $p<0.05)$. This is not unconnected with play pattern of the males which is more than that of the female as observed during the study. It further confirmed that activities such as walking bare-footed can predispose them to infections (Table 2).

Table 2. Prevalence of intestinal parasite infection in relation to sex

\begin{tabular}{lll}
\hline Sex & No. Examined (\%) & No. Positive (\%) \\
\hline Male & $146(57.48)$ & $96(37.8)$ \\
Female & $108(42.52)$ & $52(20.5)$ \\
Total & 254 & $148(58.3)$ \\
\hline$x^{2}$ calculated $=46.14, \mathrm{x}^{2}$ table $=3.841, \mathrm{df}=2,(\mathrm{P}<0.05)$
\end{tabular}




\section{CONCLUSION}

Findings from this study revealed that four geohelminthes (Fasciola spp, T. trichiura, A. lumbricoides, Hookworm and E. vermicularis) were encountered in the study area and every strategy to mitigate the infection should put into consideration the above mentioned geohelminthes. This was a reflection of the

\section{REFERENCES}

Anumba, J.U., Onyido, A.E., Eneanya, C.I., Umeaneto, P.U., Iwueze, M.O., Okafor, E.N., and Chukwuezekezie, O.C. (2016).Gastro-intestinal parasites among children in some orphanages of Anambra State, Nigeria.TheNigerian Journal of Parasitology, 37(2):135-141.

Badaki, J.A., Shitta, K.B. and Akogun, O.B. (2005).Geohelminthiasis amongst school children in two Local Government Areas of Taraba State, Nigeria.Journal of Tropical Biosciences, 5(1):38-41.

Cheesbrough, M. (1992). Medical Laboratory Manual for Tropical Countries. Second Edition, University Press Cambridge, 200357.

Dada-Adegbola, H.O., Oluwatoba, A.O. and Falade, C.O. (2005). Prevalence of multiple intestinal helminths among children in a rural community.African Journal of Medical Science, 34(3):263367.

Eke, S.S., Omalu, I.C.J., Otuu, C.A., Salihu, I.M., Udeogu, V.O., Hassan, S.C., Idris, A.R., Abubakar, N.E. and Auta, Y.I. (2015). Prevalence of Geohelminth in soil and primary school children in Panda Development Area, Karu Local Government Area, Nasarawa State, Nigeria. The Nigerian Journal of Parasitology, 36(2):91-95.

Erko, B. and Medhin, G. (2003). Human helminthiasis in Wondo Genet, Southern Ethiopia, with emphasis on geohelminthiasis. Ethiopia Medical Journal, 41(4):33-44.

Feachem, R.G. and Jamison, D.T. (1991).Disease and Mortality in sub-saharan Africa. Oxford University Press.750pp.

Glickman, L.T., Camara, A.O., Glickman, N.W. and McCabe, G.P. (1999). Nematode intestinal parasite of children in rural Guinea Africa:Prevalence and relationship to geophagia. International Journal of Epidemiology, 28:169-174.

Merid-Hegasy, T., Metete, L. and Teklemariam, I. (2001). Original article on intestinal helminthic infection among children at Lake Awusa Area, South Ethiopia. Ethiopian Journal of Health Development, 1(15):31-38. poor state of hygiene and high rate of asymptomatic carriers in Lokoja metropolis. Improved sanitation by provision of modern toilet facilities, health education by enlightenment campaigns, school-based health programme and regular early deworning of pupils would go a long way in reducing infection.

Ndamukong, K.J., Ayuk, M.A., Dinga, J.S., Akenji, T.N. and Ndoforchu, V.A. (2000). The pattern of soil-transmitted nematodes infections in primary school children of the Kumba Health District, South-West Cameroon.Africa Journal of Health Science, 7(3-4), 103-106.

Ndenecho, L., Ndamukong, K.J. and Matute, M.M. (2002.Soil-transmitted nematodes in children in Buea Health District of Cameroon.East African Medical Journal, 79(8):442-445.

Obiukwu, M.O., Umeanaeto, P.U., Eneanya, C.I. and Nwaorgu, G.O. (2008). Prevalence of gastro-intestinal helminths in school children in Mbaukwu, Anambra State, Nigeria. Nigerian Journal of Parasitology, 29(1):15-19.

Ogbe, M.N., Edet, E.E. and Isichel, N.N. (2002). Intestinal helminth infection in primary school children in areas of operation of Shell Petroleum Development Company of Nigeria (SPDC) Western Division in Delta State.TheNigerian Journal of Parasitology, 23:100-107.

Oyerinde, J.P.O. (1999). Essentials of Tropical Medical Parasitology. University of Lagos Press, Akoka, Lagos, Nigeria, pp. 347-358.

Phiri, K., Whilty, C.L.M. and Graham, S.M. (2002).Urban/rural differences in prevalence and risk factors for intestinal helminth infection in southern Malawi.Journal of Parasitology, 18:461466.

Shitta, K.B. and Akogun O.B. (2017).Intestinal helminth infections among the nomadic Fulanis in two localities of Adamawa State, North-East Nigeria.TheNigerian Journal of Parasitology, 38(1):69-73.

Stephenson, L.S. (1994). Helminth parasites, a major factor in malnutrition. World Health Organization Forum 15:169-172.

Ugbomoiko, U.S., Onajole, A.T., Edungbola, L. (2006).Prevalence and intensity of geohelminthes infection in Oba Ile Community of Osun State, Nigeria. The Nigerian Journal of Parasitology, 27:6267.

World Health Organization.(1991). Basic Laboratory Methods in Medical Parasitology. Geneva, Switzerland. World Health Organization. 